\title{
The Affectibility Concept in Systems for Learning Contexts
}

\author{
Elaine C. S. Hayashi \\ Institute of Computing - UNICAMP
}

\author{
M. Cecília C. Baranauskas \\ Institute of Computing \& \\ Nucleus of Informatics Applied to \\ Education - UNICAMP
}

\begin{abstract}
As the focus of interest in HCI research expands, new design approaches are needed. Interaction designers, who have been guiding their endeavors for better user interfaces by the concepts of usability and accessibility, are now having the opportunity to look into faces of usability not yet deeply explored: the affective and emotional ones. As an emerging subject, the need for models that associate emotions and affective quality with human-computer interaction design is still scarce. In this paper, a literature review - and its critical analysis about existing frameworks and models - organizes the state of the art about emotional quality towards the design of learning and educational systems. An experiment performed in the setting of an elementary school illustrates our proposal. From both the review and the experiment, we present the concept of Affectibility as the guiding notion from which the use and design of system-user interaction could be treated. Affectibility refers to the aspects that make the system of good - or bad - affective, emotional and hedonic qualities, potentially evoking certain affective responses in the users.
\end{abstract}

\section{Introduction}

As computers and technology evolve, so does the relationship between humans and digital artifacts, bringing new challenges to researchers in the Human-Computer Interaction (HCI) field. The paradigm shifts that follow this evolution goes from the modest concern in adjusting man-machine interaction and fixing specific problems (1st paradigm), passes through the need of accurately modeling human's actions (2nd paradigm) until the explicit focus on values in design (3rd paradigm) [20]. Indeed, the changing societies and their new ways of interacting with technology are demanding from HCI more focus and attention to human values [41]. The value-centered [19] or value-sensitive design [13] emphasizes human-beings (and their needs and desires) in the design, research and development of technology. In this sense, among the elements that still need to be incorporated into theory and practice of HCI are culture and emotion [6][20].

This is necessary because computer systems are no longer there for the sole purpose of helping us to complete our tasks. Information and Communication
Technologies (ICT) are part of our lives and influence the structure of our social liaisons [8].

One of the challenges of the HCI research in the 3rd paradigm is to give support for situated action in the world, profiting from standards that are common in the research from the 1st and 2nd paradigms, but without being limited by those standards.

This work is concerned with the interrelationship of digital artifacts and humans (more specifically, children) in their environment (school, home, neighborhood, etc), considering the constructions (of meaning, liaisons, knowledge, etc) that take place in this environment. This work involves the ecosystem that surrounds children in learning context and it is in most part situated in the 3rd paradigm of HCI research, but still counting on the pragmatic and objective details from the other two paradigms.

More recently, the sense of well-being, as well as the importance of emotional and affective qualities in technological artifacts are being recognized. For Norman [34] affective/emotional issues and usability are complementary to one another and necessary for the creation of good projects. The author defines affect as a more general term that applies to a system of judgments - which can be conscious or unconscious. Emotion, for Norman, is the conscious experience of affect, i.e., it is the affect, after being interpreted and having its cause and object identified.

We share Norman's understanding of emotions, as well as Boehner et al. [5]'s view of emotion as a social and cultural product. For [5], emotions are collectively created and experienced through interactions. The experience of an emotion is based on cultural and social contexts. For instance, the sensation of being frustrated is grounded on a context that gives meaning to frustration and that determines a response to feeling frustrated (e.g. proud, shame, lack of motivation).

Because emotions prepare, influence and/or motivate actions, they are of significant importance to human behavior, determining, among other things, the way one learns [24][27][36]. Although there are many relevant work developed or in development that cover the areas of design with children, education and learning, emotional/affective qualities of artefacts, and the intersection between each two areas, there is a lack in the investigation of 
emotional/affective issues in the design of learning mediated by technology, especially in contexts involving children as target users.

Therefore the study of usability needs to be expanded to include human values, and more specifically, the emotional values experienced within the social settings of educational groups. The objective of this paper is to review the state of the art in emotional and affective research, relating them to the design of technology for educational purposes; results of this study inform about a concept to guide a more affect-sensible design.

This paper extends our previous work [21] and is organized as follows: Section 2 presents some of the existing frameworks and models concerning three main topics: affective and emotional qualities of systems, educational systems, and design for and with children. Section 3 investigates the issue with an activity conducted with children in a real school scenario; Section 4 summarizes the preliminary thoughts towards the concept of Affectibility; and Section 5 concludes.

\section{Frameworks and models}

In this section we present some models and frameworks found in literature in one or more of the following themes: (1) emotional and affective qualities; (2) learning and education; (3) system interface design for and with children; Figure 1 synthesizes them.

(1) Based on the investigation of data collected

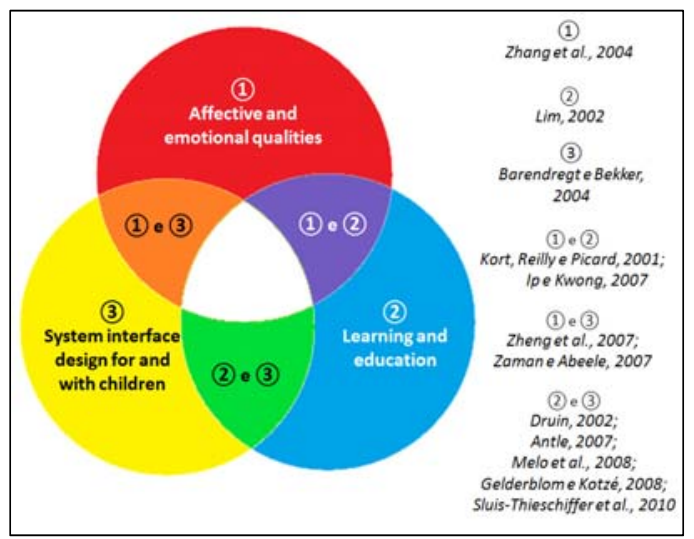

Figure 1. Some models and frameworks from literature

from students of an American university, Zhang and Li [44] built an empirical model that relates the Perceived Affective Quality (PAQ), Perceived Usefulness (PU), Perceived Easy of Use (PEOU) and the Behavior Intention (BI) in the use of technology. The results indicate that PAQ has a positive and significant impact on PU and PEOU, but the impact is not direct to BI: the effect on $\mathrm{BI}$ is mediated by PU and PEOU. For the authors, the affective reactions immediate or reflexive - that users have in relation to technology have a positive influence in the cognitive responses that such users have about the use of IT.
As a consequence, PAQ is important in the result of the evaluation of the technology in use, which brings implications to the process of design. Zhang and $\mathrm{Li}$ [44] indicate a research challenge not yet well explored: to identify if affective features are universal and can be applied to any technology, or else, if it is necessary to identify the specific affective features that suit specific types (or uses) of IT. The research question that we identify in this scenario is: what are the constructs - if there is any that may influence the affective quality that users perceive in a system? The importance of this study is related to the premise that such constructs could direct users to higher levels of motivation, by the use of digital artifacts and their interfaces.

(2) In the context of education and learning, Lim [30] proposed a framework that indicates the aspects that should be taken into account when planning the implementation of use of Information and Communication Technology (ICT) in schools. In a socio-cultural approach, Lim bases her study upon concepts from Activity Theory and uses an expanded version of the classical mediational triangle (apud [30]). In Lim's version of the mediational triangle, the tool (ICT) that used to be limited to the vertices of one user and his object is now expanded to a notion that includes communication and interaction in the social world. Applying this theory to the ecological and concentric circles from Cole and Engeström (apud [30]), the framework proposed by Lim [30] enlarges the individual and isolated approach to a proposal for the study of the group context in which the individuals are immersed.

Indeed the socio-cultural approaches are important, especially in the analysis of emotional and affective aspects. Emotions are constructed and interpreted in their cultural contexts, and they are created and developed in a social environment [5][30]. In this way, the cultural and social aspects, together with the affective issues, should be considered in the study of technology and such a study should be conducted under a socio-technical approach.

(3) Regarding the design for and with children, Barendregt and Bekker [4] show the need of an integrated framework that organizes the usability guidelines for the design of computer games for children. The authors base their work in the theories coming from Norman [34] and propose a framework that focuses on cognitive issues and on physical actions. The contribution of their work could be even more relevant if the emotional and affective issues were treated in the framework.

A model that could represent the intersection between (3) and (1) circles is the one proposed by Zheng et al. [45]. A specific kind of emotion is studied: the surprise. Surprise is seen by the authors as an emotion that stimulates creativity. The Creativity Surprise Model [45] is presented as a guide that collects a methodology for the design of interactive and tangible systems for children. However, the affective quality matters are not explicitly articulated with the emotion of surprise. 
Another model that concerns themes (3) and (1) is the framework proposed by Zaman and Abeele [46]. Set in the context of design of technology, this model shows how the interaction between basic needs, factors from the context of society and individual characteristics affect the gratifications that children search or wish. From that interaction, the authors identify five constructs - or gratifications: social experiences, challenge and control, fantasy, creative and constructive expressions and body and senses. According to the authors, these gratifications would make products more fun and "likeable" for preschoolers.

In the intersection between circles (1) and (2), we have the proposal from Ip and Kwong [24]. After collecting the emotions considered the most relevant to learning processes, Ip and Kwong developed a computational framework that has the objective of improving the detection of affective states in order to provide dynamic feedback. In this way, the interactivity with the content would be determined by the affective state detected. By capturing the students' emotions with sensors, the system would be able to provide those students with options so that the students could, for example, return to a state of motivation whenever a state of boredom is detected. Kort et al. [27] present, in a three-axis diagram, a model that relates the phases of learning to emotions. The vertical axis represents Learning. Upward (positive) is the construction of learning, while downwards, the discarding of misconceptions that normally takes place during the learning process. In the horizontal axis are the Emotions: the positive valence is to the right and the negative, to the left. The authors identify certain emotions for each quadrant formed. A third axis would point to a threedimensional plane, representing the axis of Knowledge. The path of the students around quadrants I, II, III and IV would form a spiral along the knowledge axis. Even though some of the authors of [27] are engaged in the design of systems for children, the model that they proposed in [27] does not include specifications for the design of such systems.

In the combination of the (2) and (3) themes, there are, among others, the proposals from Gelderblom e Kotzé [16], Druin [11], SluisThieschiffer et al. [42], Antle [2] and Melo et al. [32]. A framework with design guidelines is proposed in [16]. In order to compose the list, some elements from psychology and education theories regarding children development were translated into guidelines. More specifically, the theories that originated the list of guidelines are from Piaget, Vygostsky, Case, and Fischer (apud [16]). In her framework, Druin [11] explains the roles played by children in the process of design for technology to support learning: users, testers, informants and design partners. These roles were analyzed under three aspects: the relationship these children have with adults, with technology and with the design activity and design goals. Melo et al. [32] proposed, based on Participatory Design and Organizational
Semiotic methods, a model for the process of design with and for children, in the contexts of formal and informal learning. Antle [2] went in a similar direction in her proposal, but focusing in the interaction of children with tangible systems. The author recognizes that successful results should include attention to motivational and affective factors, but she clarifies that such factors were not part of the scope of her framework.

Sluis-Thieschiffer et al. [42] propose a framework to aid designers in choosing the design technique (e.g. games, drawing, prototyping) to be used with children, according to their school year. This framework is based on the theory of multiple intelligences from Gardner [15], and it relates the type of ability that is dominant in the children in a given age with the abilities demanded by each design activity.

Alsmeyer et al. [1] developed an innovative interface (a tangible handheld tool) for the communication of emotions inside the classroom. However, their studies did not include a generalization in the format of a model that would fit the central core of Figure 1. Furtado el al. [14] also came close to this core when they proposed a conceptual framework for the design and evaluation of affective usability in educational systems for geosimulation. Yet, their work does not include the user's participation in the design process nor the use of the system by children. Moreover, their proposal is very specific for the context of geo-simulation systems.

Therefore, the central area in Figure 1, empty for now, puts in evidence an opportunity for investigation and reinforces the potential contribution of this paper, which aims at the design concerned with emotional and affective factors of children's interaction with ICT in the context of learning.

As for methods of assessing affective and emotional responses that digital artifacts may evoke from users in general (usually adults), many authors have proposed different approaches. Boehner et al. [5] see two possible groups into which these approaches can be classified: "informational" and "interactional". They call "informational" the approaches in which the emotion is seen as a measurable object of study. In this group, the authors include all research methods that intend to provide objective quantification of the emotional responses presented by users in relation to the system. These approaches allow more formal and quantitative results and are common in the field of games. Among the "informational" methods are the proposals based on measurement of biophysiological responses and their automatic translation into words that define the emotions measured (e.g. [26] and [31]).

In a different direction, "interactional" [5] is the perspective under which emotion and affect are dynamically constructed and interpreted by, with and in socio-cultural contexts. These methods value the subjectiveness and richness of different possibilities 
of interpretation for the different emotions. Among these methods are those that allow users to freely express and interpret the emotions, without providing translations or computer interpreted information (e.g. [25]).

It is possible to find examples that would fit in between the Boehner's "interactional" and "informational" methods. These approaches would be those that respect the variety of possible meanings and interpretation of emotions, are aware of the fact that emotion and affect are socio-cultural products, but that still try, in some level, to quantify, register or label the emotions felt. Norman's texts [34] indicate his agreement with the dynamic and evolutionist construction of emotions ("interactional") and, at the same time, they suggest that, once the emotions are expressed in the form of human behavior, they are no longer so subjective as the sentiments themselves; i.e., they become rather informative and measurable (“informational”).

Many other studies related to emotional and affective responses can be found. There are, among others, those that explore the identification of emotions (e.g. from a given written text, as in [29]; or from the rhythm of a person's typing in a keyboard, as in [12]); and their representation (as in [17][40][38][37][39][28] - see Error! Reference source not found.). Yet, none of these proposals consider the specificities that the constructs related to learning experiences or design with children might involve.

\section{Preliminary investigation of emotional responses of children}

The missing core that was exposed in Section 2 (illustrated by the empty center of Figure 1) is being addressed in the context of the multidisciplinary research project "Projeto XO na Escola e For a Dela" (Project XO in and outside the schools), involving the co-construction of a model for the implantation of low cost laptops in a fundamental school in Campinas City, São Paulo State, Brazil. The project counts on the participation of a group of more than 500 people, comprehending students (ranging from 6 to 15 years old), teachers and the school community - which includes other employees from the school, parents, family and neighbors. The immersion of the research team within the target users scenario is moving us to a better understanding of some of the emotional and affective issues that might take place in the learning context, directing us to the development of solutions for the design of systems' interfaces that would contribute to filling the gap that has been pointed out in the last section.
The digital artifact used in the above mentioned project is the OLPC (One Laptop Per Child) XO laptop [35]. Teachers and students from this public school are now experiencing the use of these laptops in their daily activities. These laptops, not only have wireless to connect to the internet, but they are also connected in a mesh network, which encourages collaborative work. The technological environment

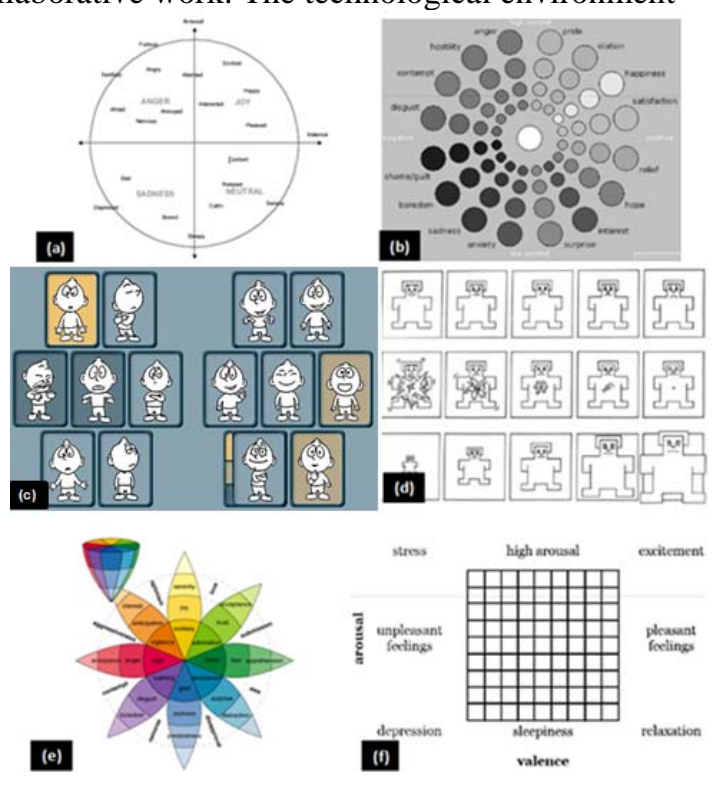

Figure 2. (a) Dimensional Affective Representation [15]; (b) GEW [38]; (c) PrEmo[36]; (d) SAM [26]; (e) Emotional Color Wheel [35]; and (f) Affective Grid [37]

available for these laptops represents a rich field for exploring the idea of expressing emotion in and through the system. One example that is being considered is the development of a simple file management system, to be designed for and with the school community. This application should manage not only the files (e.g. pictures, text, videos) shared by teachers and students, but also the representation of emotions felt during the activities when these files were produced. Students would have the opportunity (but not the obligation) to ponder and share their emotional and affective states. While students will become more aware of their own feelings, teachers could monitor the states of the entire group throughout the semesters and might even compare the results of the use of different educational approaches.

Periodically, researchers meet with teachers, students and other school's employees in workshops to share the experiences they had with the laptops and plan conjoint actions. 


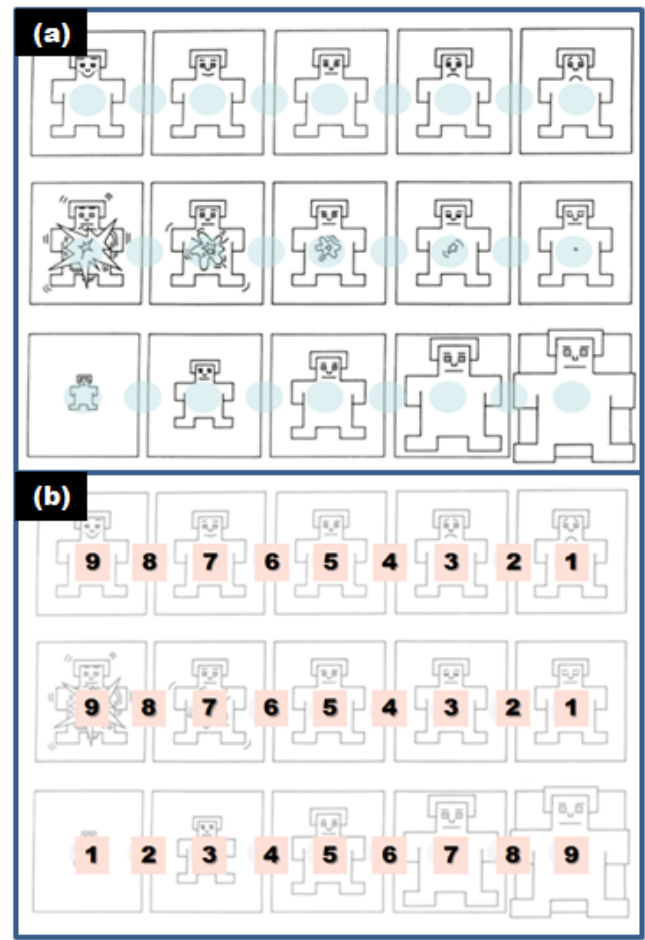

Figure 2. (a) The Self Assessment

Manikin as proposed by [28]; and (b) the values attributed to each figure.

To make the most of this preliminary stage of the Project, we wanted to observe the (emotional) relation the children first establish with the XO. For that, we ran the Self-Assessment Manikin (SAM) pictographic questionnaire (Figures 2d and 3a), from [28]. Our goal was to capture the affective response of these children towards the use of the laptop, during this phase of the project.

\subsection{Participants, method and material}

An online version of SAM was designed and the children who took part in the activity (174 students) answered the questionnaire using their laptops. These students' age ranged from 6 to 11 years old and they belonged to eight different classrooms from the Elementary School.

Thirty XO laptops were prepared in a room, with the internet browsers already opened and displaying an empty SAM form. Each group was brought into the room in turns and, after brief explanation, they were given a few minutes to answer the online form. Although each child was able to take a look at his neighbor's answers, they were not asked to discuss their votes with their colleagues prior to submitting their opinions.

It took one morning to have the eight groups answered the questionnaire. The results were immediately sent to an online spreadsheet as the participants answered the forms. On the previous morning, researchers rehearsed the activity in a pilot test. In this opportunity, teachers, other school's employees, some parents and students' representatives answered the pictographic questionnaire. This rehearsal not only helped researchers to check if the online form and spreadsheet were working properly but also allowed the groups - especially teachers and the school's principal - to understand the activity to which the children would be submitted, beforehand.

SAM [28] is composed of three sets of figures that depict the ranges of emotions in three different levels - or dimensions: valence, arousal and dominance - in a 9 point scale (each set is composed of only five pictures but the space in-between pictures are also valid options). The valence dimension explores how happy-unhappy the user is in relation to the artifact being evaluated; arousal indicates the levels of excitement or boredom; and dominance indicates how "in control" of the artifact the user feels himself/herself (in other words, how comfortable they are using it). Thanks to its text-free format, SAM can be used even in groups of younger children who are not yet fluent in reading and understanding written words. Moreover, this pictographic form avoids possible misunderstandings that the labeling of emotions into words might bring about. SAM was successfully used by other authors in various contexts (e.g. [7][9][22])

Figure 3 shows (a) the original SAM, as proposed by [28] and (b) the values attributed to each figure to determine and manage ratings and results. The number 9 was assigned to the most positive alternative of each sequence (therefore the order in the third row is different from the other two).

\subsection{Results}

After the activity, the results gathered at the online spreadsheet were coded (according to Figure 3b) and analyzed. In general, it seems that the XO laptop is being very well accepted by the students, as the results show positive numbers. Figure 3 illustrates the percentage of choices from each dimension. This graph shows that even though some children are not (yet) totally familiar with the laptop (only 69\% chose the maximum score 9 for the laptop $\mathrm{XO}$ at the dominance level), they enjoy using it (93\% rated 9 at the valence level).

This activity was an initial step to approach the subject in a real scenario of a Brazilian public school where the laptops are being introduced in children's practice; it is worth mentioning that this represents the first and, in many cases, only opportunity these children are experiencing regarding technology.

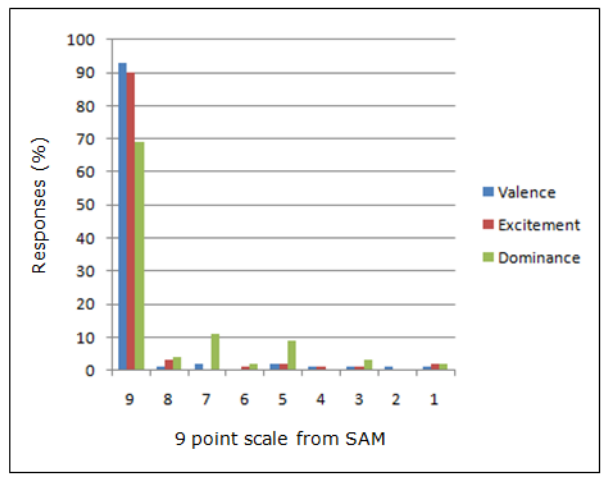

Figure 3. Percentage of responses 
This attempt to assess the affective and emotional responses of users towards the laptop is only part of our endeavor to investigate the relationships between the design, users and artefacts. The design for systems that is concerned with affective, emotional and hedonic qualities of interaction might include evaluations of responses such as the one we performed in this activity, but there are other aspects that should also be considered. The entire picture that includes this attempt and other constructs is presented in the next section.

\section{Towards an Affectibility Framework}

In the broader context in which all these frameworks (i.e. from Section 2) and activities are immersed lies the concept of Affectibility. We are defining Affectibility as an aspect of usability related to the characteristics of an artifact that may evoke emotional and affective states in those who interact with that artifact.

Hoonhout [23] used the word Affectability as the wording for "affective product qualities", as he defines in a footnote in [23], while discussing about the design of products that are intended to be fun. Although the entries "affectability" and "affectibility" were not found in more traditional dictionaries like Oxford, MerriamWebster or American Heritage, popular online dictionaries present some definitions. The Dictionary.com [10] defined "affectability" as related to the verb "to affect" and "affectibility" as "the quality or state of being affectible”.

The concept of Affectibility is suggested here as a guiding notion from which the use and the design of system-user interaction could be handled. It goes further than the term Affectability proposed by Hoonhout [23], which considers mainly the fun facet (the hedonic qualities) of the matter. It is worth noticing the difference in the composition of the words, as the word affectability, with an "a”, might suggest the ability to affect (produce an effect on) something. We define Affectibility as the subjective measure that denotes the capacity of an artifact to evoke users' varying degrees of emotional and affective responses during the use of such artifact (e.g. software, computer, handheld). It also includes the hedonic qualities of the artifact - but it is not limited to that. While Likeability is mainly concerned with the design and evaluation of applications that are aimed to be fun [46], Affectibility is related to the design and evaluation of digital artefacts focusing on general qualities of emotional responses.

Similarly to the concepts of Learnability and Playability, Affectibility refers to the aspects that make the system of good - or bad - affective, emotional and hedonic qualities, potentially evoking certain affective responses in the users. It is important to study aspects of Affectibility, as in the context of children's education; they might bring impacts on their learning processes.
Like Usability, Affectibility is a characteristic of the artifact (relative to a user) and not a characteristic of the user (i.e. in an Affectibility Evaluation, the object under evaluation is the artifact and not the users and their affective states). The nature of this quality may vary depending on the purpose of the artefact. For example, for a sci-fi educational game application, the raising of arousal and tension levels in the user might be a positive aspect. Moreover, the context of use (socio-cultural aspects) may also have influence in this valence. As mentioned before, the way people interpret and understand the emotions is constructed in the society they live. This means that, for a computer system to be considered of good or bad Affectibility, a myriad of factors need to be considered. Therefore, when aiming at specific affective responses to be evoked by the interaction with a digital artifact, the designer should take into account not only the context of use, but also the subjective processes (e.g. cognitive, emotional) from diverse users. How affective states are interpreted is an example of a question to be investigated in this model. This relationship between the artifact and the users is represented in the right side of Figure 5.

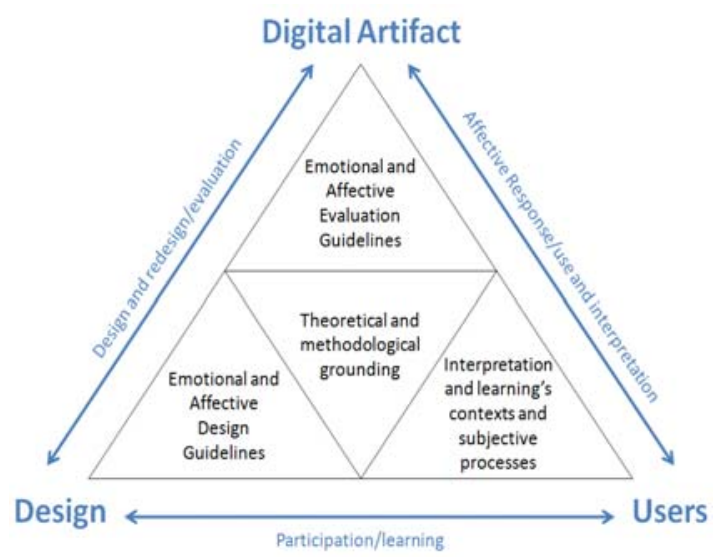

Figure 4. Proposed Affectibility Model for the design of computational systems

Figure 5 illustrates our first approach in the direction of an Affectibiliy Framework for the design of digital artifacts. The design of such artifacts (represented in the left side of the figure) is an iterative process. Principles and guidelines are needed to direct the design for Affectibility. Due to its subjective nature, the design for Affectibility might demand rather heuristic methods then fixed algorithmic rules or specific guides. The same is valid for the affectibility evaluation.

These processes (design and evaluation) should try to answer questions such as: How can the desired affective state be evoked in the users by interacting with the system-user interface elements? How could the users' emotional responses be made explicit in order to evaluate the Affectibility of the system?

The activity presented in Section 3 is only one of the possible practices that could be performed in the sense of evaluating the Affectibility of an artefact. Other approaches and methods need to be tried 
and/or combined, not only to evaluate the system but also in order to better understand the constructs involved that determine how users are likely to respond to the system.

"Users" is stated in the plural as, especially among children, the opinion of the group might exert an important role in the opinion of the individual while interacting together, impacting in their responses towards the system. It also indicates the collective aspect of the creation of emotions.

Effective users' participation throughout the entire design process allows for results that make more sense to them, as reported in previous work [33]. During the process of design, the users that participate on it have the opportunity to learn about their emotions and reflect on the way they react or manage their responses.

Theoretical and methodological grounding. The center of Figure 5 depicts the core of the model: a system of theories and methods that forms the basis and connects the other elements of the model. Here we include Norman's propositions on emotions [34] and the "interactional", "informational" [5], and in between approaches - described in Section 2 - for eliciting and measuring users emotions.

As pointed out in Section 2, it is necessary to consider the social and cultural contexts when applying the use of ICT in schools, especially in the design of systems involving the awareness of emotional and affective states by the students. In this sense, the methodology involved in SemioParticipatory workshops [3][33] is applied in this model, as they enable designers to be immersed in the broader context of use and allow participants to be deeply involved in the entire process. Other investigations have shown that these methods are sound and appropriate for this purpose [32][43].

Emotional and affective design guidelines. As mentioned before, due to the unique and individualized characteristics of emotion and affect manifestations, the principles to support the interaction design for Affectibility should be composed of rather heuristic strategies. Not only that, the guidelines should be constructed together with each target group of users in order to provide results that make sense to them. The system of methods described in the previous paragraph offers tools to allow the collective construction needed. Some basic invariants that could be applied in diverse scenarios can be found, and the proposal of such set of guidelines is in the scope of our ongoing work.

Emotional and affective evaluation guidelines. An iterative design process calls for constant evaluation of the digital artifact being constructed. But not only designers are responsible for the artifact's evaluation. Final users are also constantly providing feedback about their emotional response during the use of the resulting systems. The model presented in Figure 5 illustrates the relation with the digital artifact from both sides: designers and users, as they meet to form the principles for the evaluation of affectibility. This flow should allow the artifact to evolve together with the users. It is necessary to investigate how the approaches described in Section 2 might be adapted or combined to be used as methods for evaluating the digital artifact in the scenario specified in this work.

Interpretation and learning contexts, and subjective processes. Users' affective and emotional responses towards the use of the artifact are the result of subjective processes. Similarly, the way users interpret others' emotions are also particular and may vary from culture to culture. In this sense, if the artifact should allow users to represent their affective states, then proper concern should be given to avoid misunderstandings among different users, especially in the cases where a system is expected to be used world widely. This is one example of an issue to be pondered while describing principles for the design concerned with Affectibility. Regarding the relationship of users with the design process, when actively participating in the design activities, users learn with the system and with designers. The impact that the design processes have on children are often neglected [18]. Moreover, users also provide emotional feedback during the design activities and this data should not be overlooked by designers, as they might influence or be useful to the results.

The proposed Affectibility model aggregates the concerns that we have pointed out. The complete group of principles and guidelines resulting from the model might contribute to the improvement of digital educational artifacts’ usability.

\section{Conclusion}

The emotional and affective design of computational artifacts brings many challenges to the study of Human-Computer Interaction. The literature review on existing models and frameworks has put in evidence new opportunities for investigation.

The identification and evaluation of affective quality in computer systems, as well as the interpretation of users' emotional response towards the interaction with the system are challenges that have not yet been deeply investigated, especially in the context that could most profit from this knowledge: the context of children learning and interacting with the use of technology.

As the starting point in this investigation, we proposed a concept to enrich and broaden the scope of Usability - the Affectibility, raising its foundations and showing preliminary results of exploring the subject in a real scenario. The overall result of the activity indicates that it is possible to objectively express the rather subjective emotional responses raised by digital artifacts. This possibility may inform the development of guidelines for evaluating systems designed for/in educational contexts - as part of an Affectibility framework.

\section{Acknowledgments}

We would like to thank CAPES (Process \#01P04388-10) and CNPq (Processes \#475105/2010-9 and \#560044/2010-0) for financial support, and our 
colleagues from InterHAD, NIED and IC UNICAMP for insightful discussions.

\section{References}

[1] Alsmeyer, M.; Luckin, R.; Good, J. "Developing a Novel Interface for Capturing Self Reports of Affect," in Proc. of CHI 08, Florence, Italy, 2008, pp. 2883-2888.

[2] Antle, A. N. "The CTI Framework: Informing the Design of Tangible Systems for Children," in Tangible and Embedded Interaction (TEI 2007), Louisiana, 2007, pp. 195 - 202.

[3] Baranauskas, M. C. C. "Socially Aware Computing," in: ICECE 2009 VI International Conference on Engineering and Computer Education, 2009, Buenos Aires. Proc. of VI International Conference on Engineering and Computer Education. Buenos Aires, 2009. p. 1-5.

[4] Barendregt, W.; Bekker, M. M. "Towards a Framework for Design Guidelines for Young Children's Computer Games," in Proc. of the 2004 ICEC Conference. Eindhoven, The Netherlands, 2004, pp. 365-376.

[5] Boehner, K., DePaula, R.,Dourish, P., Sengers, P. "How Emotion is Made and Measured," in International Journal of Human-Computer Studies, Vol. 65, Issue 4, April 2007, pp. 275-291.

[6] Bødker, S. "When second wave HCI meets third wave challenges," in Proc. of the 4th Nordic Conference on Human-Computer Interaction: Changing Roles. ACM, New York, NY, 2006, pp. 1-8.

[7] Cai, H.; Lin, Y. "Modeling of operators' emotion and task performance in a virtual driving environment," in: International Journal of Human-Computer Studies, vol. 69, issue 9, August 2011, pp. 571-586.

[8] Castells, M. "The Rise of the Network Society, The Information Age: Economy, Society and Culture Vol. I.” Cambridge, MA; Oxford, UK: Blackwell, 2000.

[9] Chorianopoulos, K., Spinellis, D. "User interface evaluation of interactive TV: a media studies perspective," in Universal Access in the Information Society 5, 2, Springer, Heildelberg, 2006, pp. 209-218.

[10] Dictionary.com. http://dictionary.reference.com/ (Accessed in May, 2011).

[11] Druin, A. "The Role of Children in the Design of New Technology,” in Behaviour and Information Technology, vol. 21, n. 1, 2002, pp. 1-25.

[12] Epp, C., Lippold, M., Mandryk, R. L. "Identifying Emotional States using Keystroke Dynamics," in: Proc. of CHI 2011, 2001, pp. 715-724.

[13] Friedman, B., Kahn, P. H., Jr., and Borning, A. "Value Sensitive Design and information systems," in: HumanComputer Interaction and Management Information Systems: Foundations. M.E. Sharpe, Armonk, N.Y., 2006, pp. 348-372.

[14] Furtado, E., Furtado, V., Vaconcelos, E. "A conceptual framework for the design and evaluation of affective usability in educational geosimulation systems," in: Proc. of INTERACT 2007, Rio de Janeiro, 2007, pp. 497-510.

[15] Gardner, H. "Frames of Mind." Ed. 2004. New York, New York, NY: Basic Books, 1983.

[16] Gelderblom, H.; Kotzé, P. "Designing technology for young children: what we can learn from theories of cognitive development," in: Proc. of SAICSIT'08, Wilderness, South Africa, 2008, pp. 66-75.

[17] Giannakopoulos, T., Pikrakis, A., Theodoridis, S. "A dimensional approach to emotion recognition of speech from movies," in: Proc. of ICASSP IEEE International Conference, Taipei, 2009, pp. 65-68.

[18] Guha, M. L., Druin, A., Fails, J. A. "Investigating the Impact of Design Processes on Children," in: Proc. of IDC 2010, pp. 198-201.

[19] Gorguen, J. A. "Semiotics, Compassion and Value-Centered Design,” in: Virtual, Distributed and Flexible Organisations - Studies in Organisational Semiotics. Springer, 2005.

[20] Harrison, S., Tatar, D., Senger, P. "The Three Paradigms of HCI,” in: Extended Abstracts CHI 2007, San jose, CA, 2007.
[21] Hayashi, E. C. S.; Baranauskas, M. C. C. "Towards a Framework for the Affective and Emotional Faces of Usability," in: Proc. of the International Conference on Information Society (i-Society 2011), London, UK, pp. 8895

[22] Hayashi, E. C. S; Neris, V. P. A.; Martins, M. C.; Baranauskas, M. C. C.; Piccolo, L. S.; Costa, R. "Avaliando a Qualidade Afetiva de Sistemas Computacionais Interativos no Cenário Brasileiro,” in: Usabilidade, Acessibilidade e Inteligibilidade Aplicadas em Interfaces para Analfabetos, Idosos e Pessoas com Deficiência - Resultados do Workshop. Campinas: Fundação CPqD, 2009, v. 1, p. 55-62.

[23] Hoonhout, J."Let's Start to Create a Fun Product: Where is My Toolbox?", User Experience Evaluation Methods in Product Development Workshop in CHI’08, Florence, Italy, April 2008.

[24] Ip, H. H. S.; Kwong, B. "A conceptual framework of affective context-aware interactive learning media" in: Proc. of the 2nd international conference on Technologies for elearning and digital entertainment, 2007, pp. 391-400.

[25] Isbister, K., Höök, K., Laaksolahti, J., Sharp, M. "The Sensual Evaluation Instrument: Developing an Affective Evaluation Tool," in Proc. of the SIGCHI Conference on Human Factors in Computing Systems. CHI '06. ACM, New York, NY, 2006, pp.1163-1172.

[26] Khan, M. M., Ward, R. D., and Ingleby, M. "Classifying pretended and evoked facial expressions of positive and negative affective states using infrared measurement of skin temperature,” in ACM Trans. Appl. Percpt. 6, 1, Article 6 (February 2009), 2009, 22 pages.

[27] Kort, B.; Reilly, R.; Picard, R.W. "An Affective Model of Interplay Between Emotions and Learning: Reengineering Educational Pedagogy-Building a Learning Companion,” in: Proc. of ICALT 2001, Madison Wisconsin, 2001.

[28] Lang, P. J., Bradley, M. M., Cuthbert, B. N. "International affective picture system (IAPS): Instruction manual and affective ratings.” Technical Report A-6, University of Florida, 2005.

[29] Liu, H., Lieberman, H., Selker, T. "A Model of Textual Affect Sensing using Real-World Knowledge,” in: ACM Conference on Intelligent User Interfaces, January 2003, Miami, 2003, pp. 125-132.

[30] Lim, C. P. "A theoretical framework for the study of ICT in schools: a proposal," in: British Journal of Educational Technology, vol. 33, n. 4, 2002, pp. $411-421$.

[31] Mandrik, R.L., Atkins, M.S., Inkpen, K.M. "A Continuous and Objective Evaluation of Emotional Experience with Interactive Play Environment," in: Proc. of the SIGCHI Conference on Human Factors in Computing Systems. CHI'06, 2006, pp. 1027-1036

[32] Melo, A. M., Baranauskas, M. C. C., Soares. "Design com Crianças: da Prática a um Modelo de Processo" in: Revista Brasileira de Informática na Educação, vol. 16, n. 1, 2008, pp. 43-55.

[33] Neris, V. P. A., Almeida, L. D., Miranda, L. C., Hayashi, E. C. S., Baranauskas, M. C. C. "Collective Construction of Meaning and System for an Inclusive Social Network". In: International Journal of Information Systems and Social Change (IJISSC) 2011, vol. 2, issue 3, pp. 16-35.

[34] Norman, D. "Emotional design: why we love (or hate) everyday things.” New York: Basic Books, 2004.

[35] OLPC: http://one.laptop.org (Accessed in May, 2011).

[36] Picard, R.W. “Affective Computing." MIT Press, Cambridge, 1997.

[37] Plutchik, R. "Emotions and Life: Perspectives from Psychology, Biology, and Evolution,” in: APA (American Psychological Association), 1. ed., nov. 2002.

[38] PrEmo. http://www.premo-online.com/ (last access: Oct., 2010).

[39] Russell, A. J. “Affect Grid: A Single-Item Scale of Pleasure and Arousal," in: Journal of Personality and Social Psychology. Vol. 57, n. 3, 1989, pp. 493-502.

[40] Scherer, K. "What are emotions? And how can they be measured?" in: Social Science Information, vol. 44, issue 1, 2005, pp. 695- SAGE Publications. 
[41] Sellen, A., Rogers, Y., Harper, R., Rodden, T. "Reflecting human values in the digital age," in: Commun. ACM Vol. 52, n. 3 (Mar. 2009), pp. 58-66.

[42] Sluis-Thiescheffer, R. J. W.; Bekker, M. M.; Eggen, J. H.; Vermeeren, A. P. O. S.; Ridder, H. "Development and application of a framework for comparing early design methods for young children," in: Interacting with Computers, vol. 23, 1, 2011.

[43] Soares, S. C. M., Baranauskas, M. C. C., "Towards a Participatory Approach to Support Interface Customization for Groups of Children”. In: Proc. of HCII 2005.

[44] Zhang, P., Li, N. “The Importance of Affective Quality," in: Communications of the ACM. September, vol. 48, 9, 2005, pp. 105- 108.

[45] Zheng, S.; Bromage, A.; Adam, M.; Scrivener, S. A. R. "Surprising creativity: a cognitive framework for interactive exhibits designed for children," in: Proc. of the 6th ACM SIGCHI Conference on Creativity \& cognition, 2007, Washington, DC, USA.

[46] Zaman, B., Abeele, V. V.“"Towards a Likeability Framework that meets Child-Computer Interaction \& Communication Sciences," in: Proc. of the 6th international conference on interaction design and children, 2007. 